Military Technical College

Kobry El-Kobbah,

Cairo, Egypt

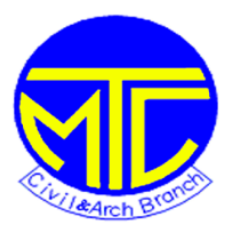

$12^{\text {th }}$ International Conference

on Civil and Architecture

Engineering

ICCAE-12-2018

\title{
EXPERIMENTAL STUDY AND NUMERICAL ANALYSIS OF PROGRESSIVE COLLAPSE RESISTANC OF A REIFORCED CONCRETE FRAME
}

\author{
Magdy A. Tayel ${ }^{(1)}$; Ghada M. Hekel ${ }^{(2)}$; Islam Ali $^{(3)}$ \\ 1- Prof. of Reinforced Concrete structures, Civil Engineering Department,Faculty of \\ Engineering, Minoufiya University \\ 2- Lecturer, Civil Engineering Department, Faculty of Engineering, Menoufia \\ University, Egypt. \\ 3- PHD student, Civil Engineering Department, Faculty of Engineering, Menoufia University, Egypt \\ Emailmagdy_tayel@hotmail.com ${ }^{(1)} d_{\text {_rghekel@hotmail.com }}{ }^{(2)}$ engeslam_ali2008@yahoo.com ${ }^{(3)}$
}

\begin{abstract}
:
The current paper investigates the problem of structural progressive collapse.A two-bay small scale reinforced concrete frame has been casted without the intermediate column and dynamically-loaded until failure in order to investigate its behavior and strength under column loss condition. During the test, deflection, cracking, longitudinal strains in both steel bars and concrete, ultimate loads and mode of failure have been monitored. Additionally, an F.E model, using Abaqus 6.13 program is presented.In the numerical model, strain rate effects have been considered. The tested frame was prepared and casted in the reinforced concrete laboratory, faculty of Engineering, Menoufia University while the testing process took place in reinforced concrete laboratory, faculty of Engineering, Tanta University.
\end{abstract}

\section{Introduction}

After several catastrophic building collapse accidents such as the total collapse of the World Trade Center towers, many research activities have led to more detailed guidelines on designing and preventing progressive collapses (e.g. [1-3]). Dealing with preventing progressive collapse in a certain building depends on its degree of importance; for law importance buildings, local failure is allowed and hence, alternative load paths must be considered. On the other hand, for highly importance buildings, no local failure is allowed. So, a special care should be paid during the design of the main elements as they mist sustain possible accidents. More detailed information on the state-of-the-art in the field of progressive collapse can be found in [3-8]. Following the issue of the guidelines [1,2], several research papershave been published presenting numerical analyses concerning progressive collapse of steel and reinforced concrete structures. To give a few examples of recent studies, Marjanishvili and Agnew [9], analysed a model of a nine-story steel moment resistant frame building applying four methods of the indirect approach using SAP 2000 finite element software. Similarly Fu [10] considered a twenty-story steel composite frame building model under column removal using ABAQUS. Tsai and Lin [11] investigated progressive collapse resistance of an earthquakeresistant reinforced concrete building model subjected to column failure using SAP 2000. Kwasniewski [12] analyzed eight-story steel building using LS-DYNA software focusing on 3D detailed modeling and identifying critical parameters for the potential of progressive collapse. Recently, Iribarren et al. [13] used a more sophisticated approach consisted of a detailed modeling of reinforced concrete cross-sections to analyze a five-story RC planar frame model. [14]Wang,Wei study the Slab effect of composite subassemblies under a column removal scenario.Bo Yang[15] studythebehaviour of composite beam-column joints under a middle-column-removal scenario 


\section{Experimental Program}

\subsection{Description of the tested frame}

In order to study the failure mechanism due to dynamic extreme loads, a 3D RC frame was designed as a reduced order model of a prototype one-story RC frame structure. The structure consists of two successive frames separated by three beams. Each frame is two bay-one story with $1 \mathrm{~m}$ story height and $1 \mathrm{~m}$ bay width. The two frames are $1 \mathrm{~m}$ apart. The front frame has been casted without the middle column in order to study the progressive collapse. The model was built on a strip foundation that was supported on a strong steel floor during testing process. The structure model dimensions are shown in figure (1). 

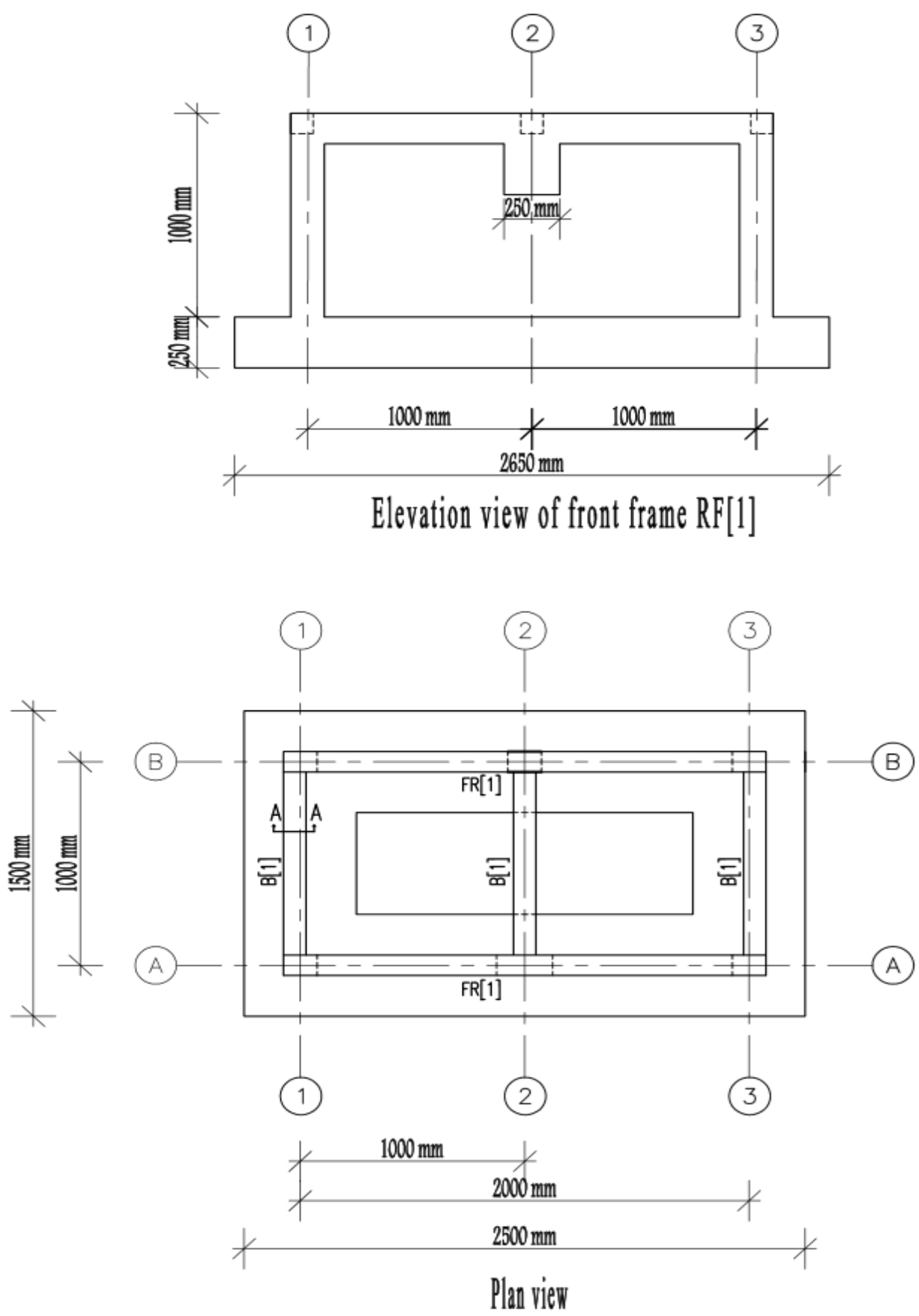

Figure (1): Dimensions of tested frame

High tensile steel with $10 \mathrm{~mm}$ diameter was used as tension and compression reinforcement while mild steel with $6 \mathrm{~mm}$ diameter was used as shear reinforcement. Reinforcement of frame was calculated according to the requirements of concrete design code [16]. The reinforcement details of beams, columns, and beam column joints are provided in Figure (2). 

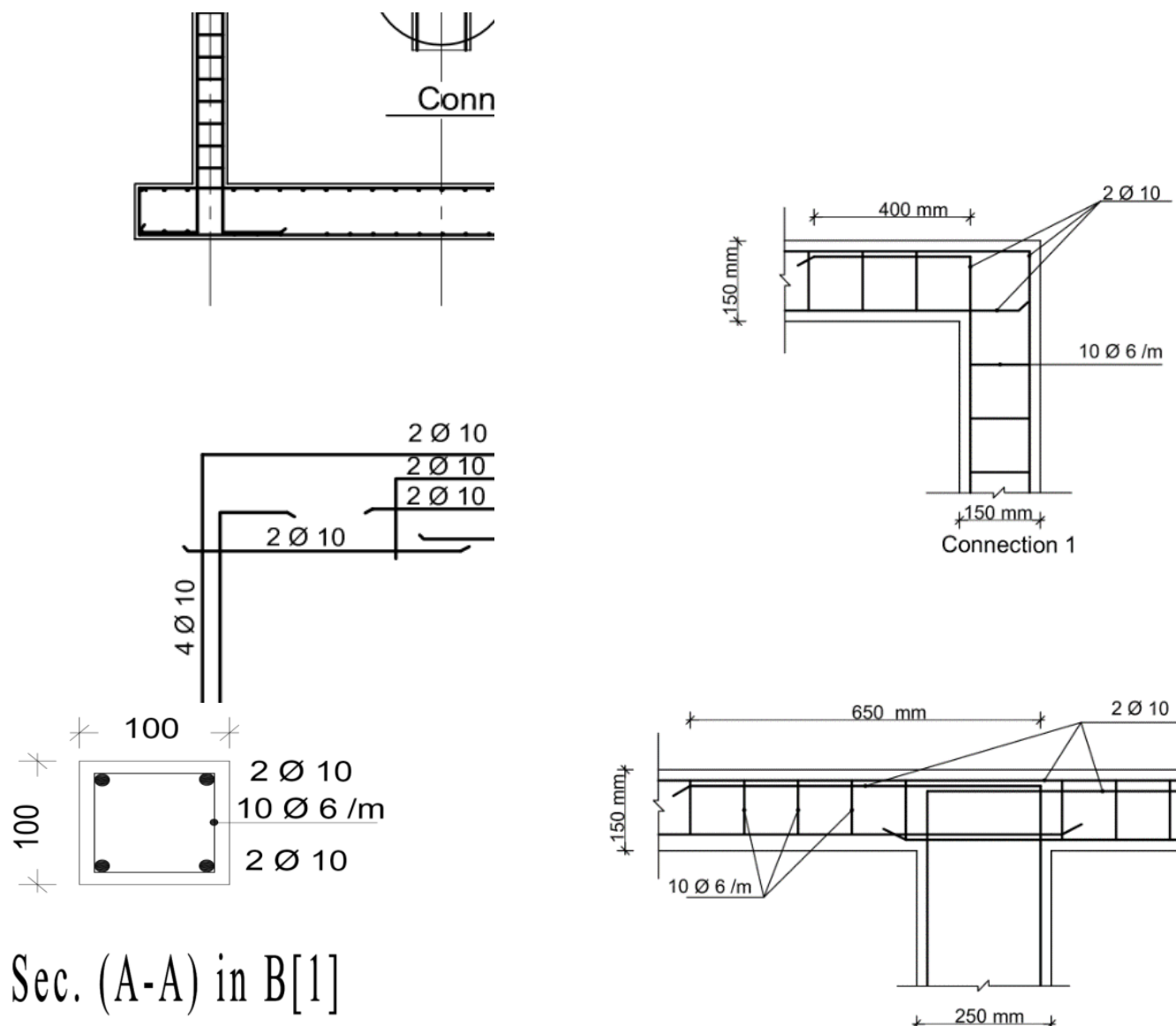

Figure (2): Reinforceme

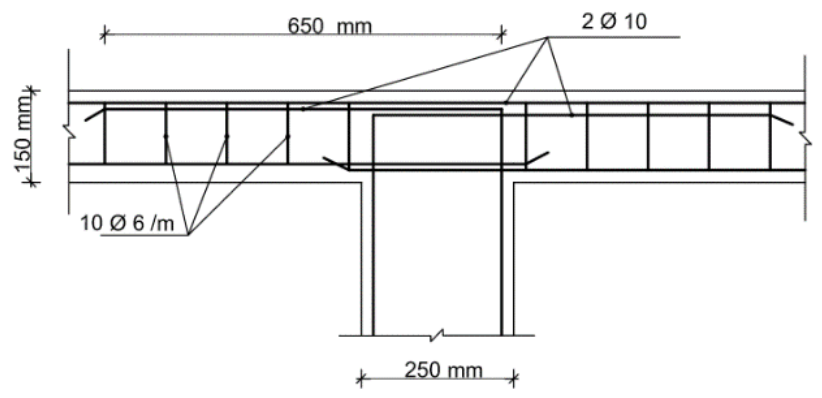

Connection 2

\subsection{Concrete mix design and properties}

In order to avoid nesting that could occur in small sections of the frame, Self-Compacted Concrete (SCC) was selected due to its high workability and suitability to fill the narrow sections in addition to its high strength. Table (1) gives the mix proportions to produce one cubic meter of SCC.

Table (1): Mix quantities to produce $1 \mathrm{~m}^{3}$ of self-compacted concrete.

\begin{tabular}{||l||c|c|c|c||c||c||}
\hline \hline Constituent & Cement & Sand & Dolomite & Fly Ash & Viscosity enhancing agent & Water \\
\hline \hline Quantity $\left.\mathbf{( K g} / \mathbf{~ m}^{\mathbf{3}}\right)$ & 400 & 1000 & 1000 & 40 & 10 & 120 \\
\hline
\end{tabular}

Both compression and tensile strengths of the concrete mix were determined experimentally where concrete cubes and cylinders were prepared to match the casting conditions of the test specimens; however, the testing procedure for the compressive strength of the cubes followed Egyptian Standard Specifications, ES1658-4/2008, and ISO19203/2004 [17].The compressive and tensile strengths were found to be $42 \mathrm{MPa}$ and $3.8 \mathrm{MPa}$ respectively.

\subsection{Casting of frame}

According to the Egyptian Code of practice [16], the framepreparation, Casting and curing were done in the reinforced concrete laboratory, Faculty of Engineering, Menoufia University. 
Casting process has been done in two steps; in the first step, two meshes of steel, representing footing reinforcement,were conducted and then placed to their correct position in mold. Four steel bars were placed in each columns positions as shown in figure (3) then the footing was casted.

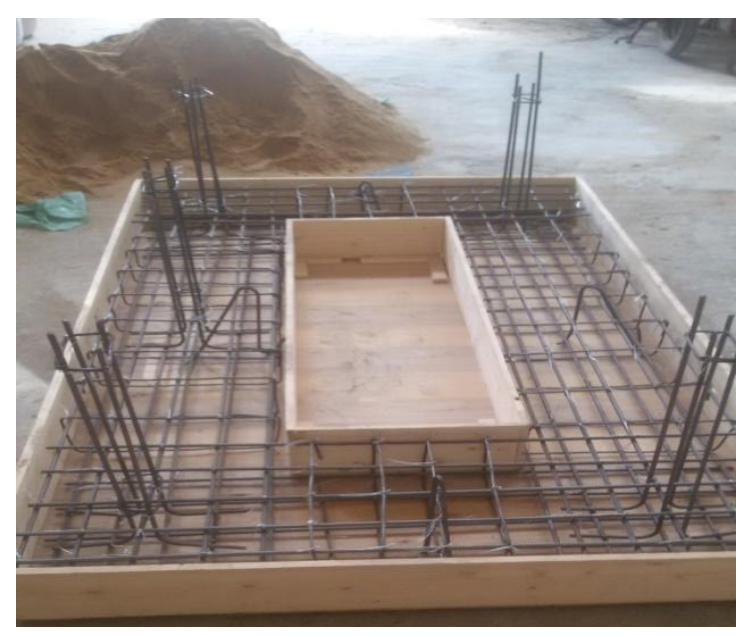

Figure (3): Steel reinforcement of foundation and column indication.

After 7 days, the main reinforcement of the entire frame was conducted and then the stirrups were placed in their positions. To measure the strain in tension reinforcement during loading, three strain gauges were mounted at the possible locations of maximum tension. In order to place the strain gauges, the surface of the reinforcing bar was groundto flatten the surface, then it was cleaned. After wiring the strain gauges, they were coated with silicon to protect them from damage during the placement of the concrete. Then, this cage was placed into its correct position. The reinforcement cages of the three secondary beams were conducted using main steel and the stirrups were placed in position. Then the reinforcement cage placed at its position of frame as shown in figure (4). After finishing reinforcement placing, the process of form work was begun. Sufficient care was taken during casting process to avoid displacement of the reinforcement inside the form work. Finally, the surface of the concrete was leveled, finished and smoothened by metal trowel and wooden float. The finishing surfaces of concrete are shown in figure (5).

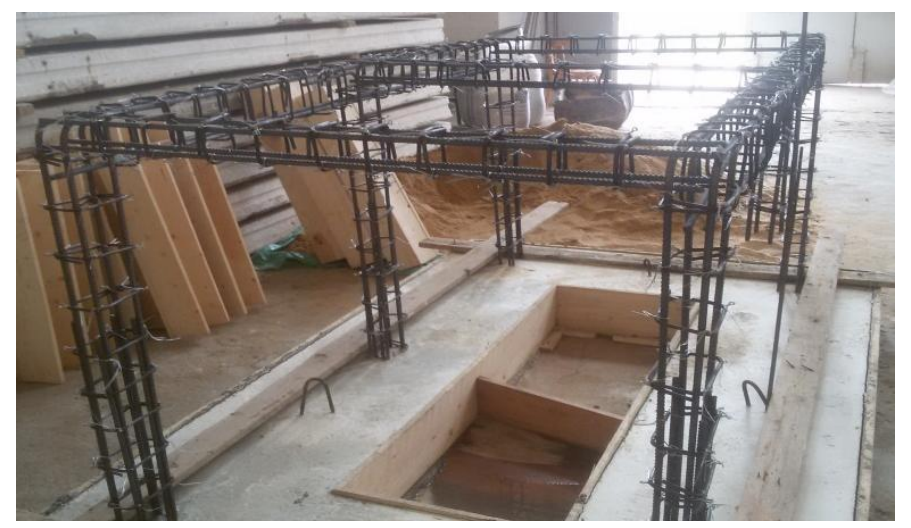

Figure (4): Reinforcement details of beams and columns of frame 


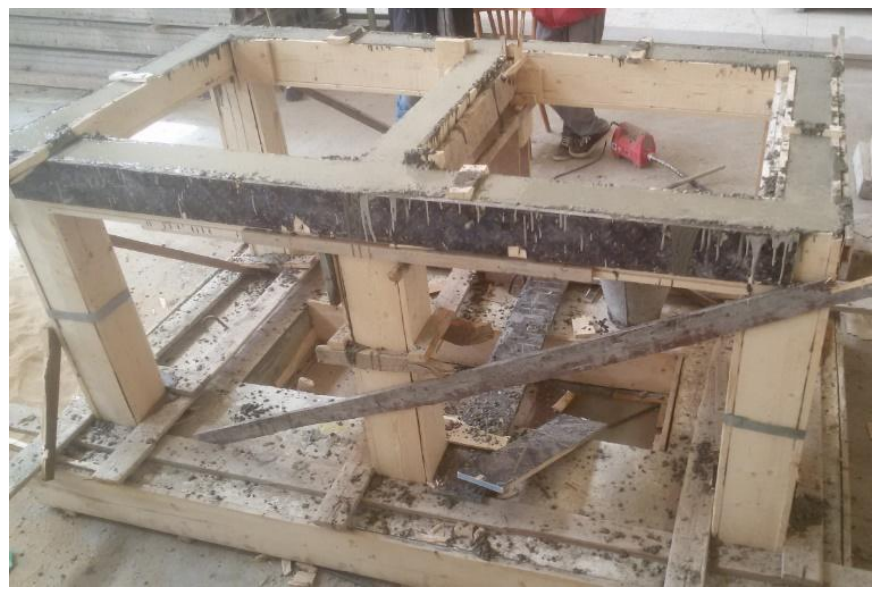

Figure (5): Finishing surface of concrete

\subsection{Instrumentation and test setup}

\subsubsection{Test setup}

The experimental setup is illustrated in Figure (6).Load was applied with an MTS (Material Testing System) hydraulic actuator of as shown in the figure. In the test, HPU (hydraulic power unit) was responsible for generating pressure to the oil and to control the oil temperature. HSM (hydraulic service manifold) was responsible for manifold oil. A computer, located in the control room was used to control all other devices. The load from the actuator was distributed into central point of beam of FR[1] by rigid plates. The vertical deflection under the loading point was recorded. The horizontal displacement at mid-point of connection of columns and beams of FR[1] were recorded using two standard LVDTs (linear variable displacement transducer) of sensitivity $0.01 \mathrm{~mm}$ as shown in Figure (7). Electrical strain gauges shown in Figure (8), of gage length 10mm and resistance 120 Ohms, were used to measure strains at the possible locations of maximum tension in longitudinal main reinforcement. All readings were recorded using data logger (sensor interface PCD-300A/320A). Behavior of the RC frame during the test was monitored.

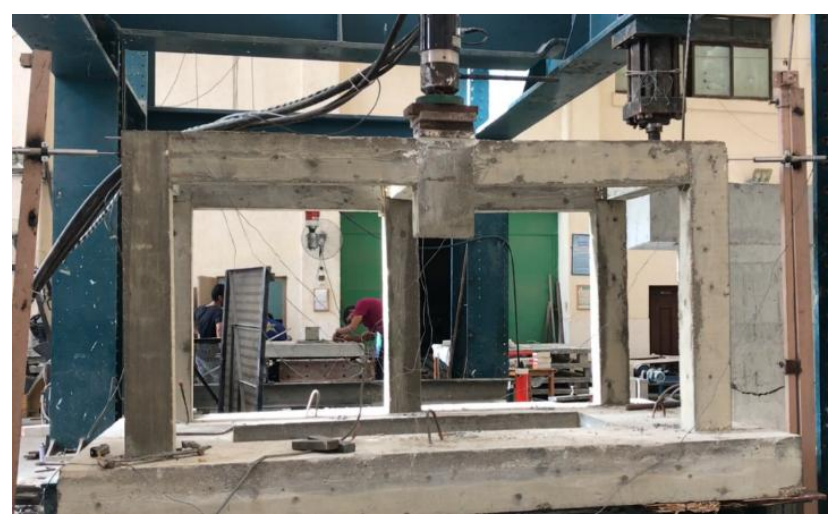

Figure (6): Experimental set-up 


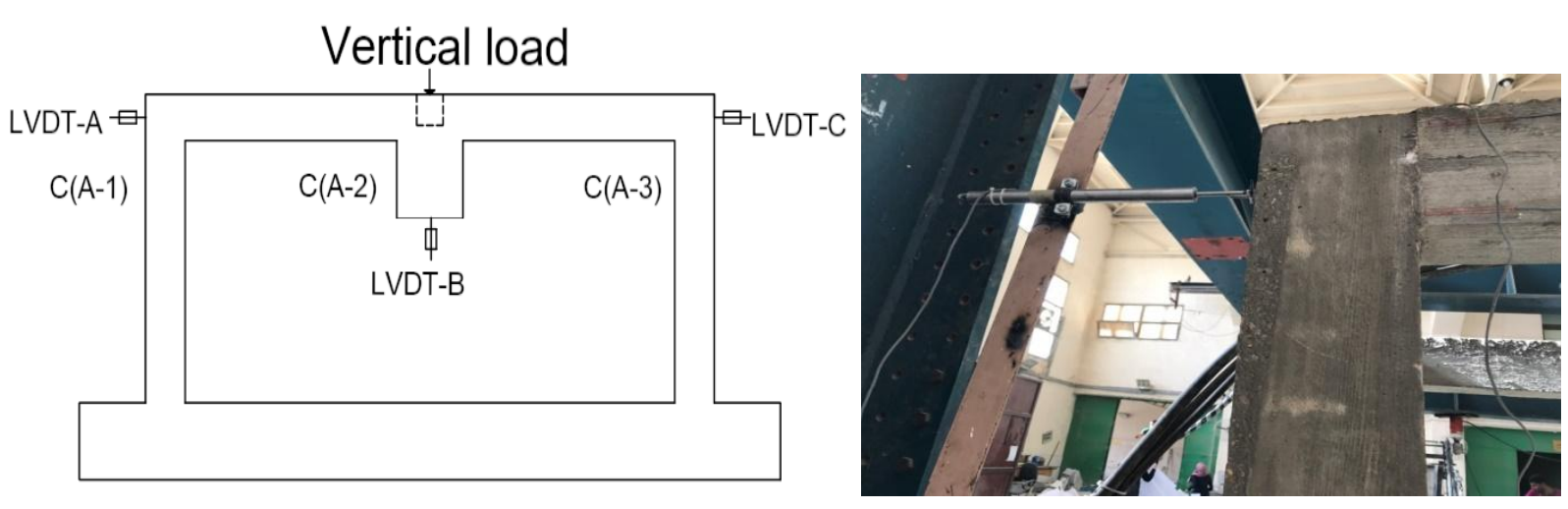

Figure (7): The locations of LVDTs
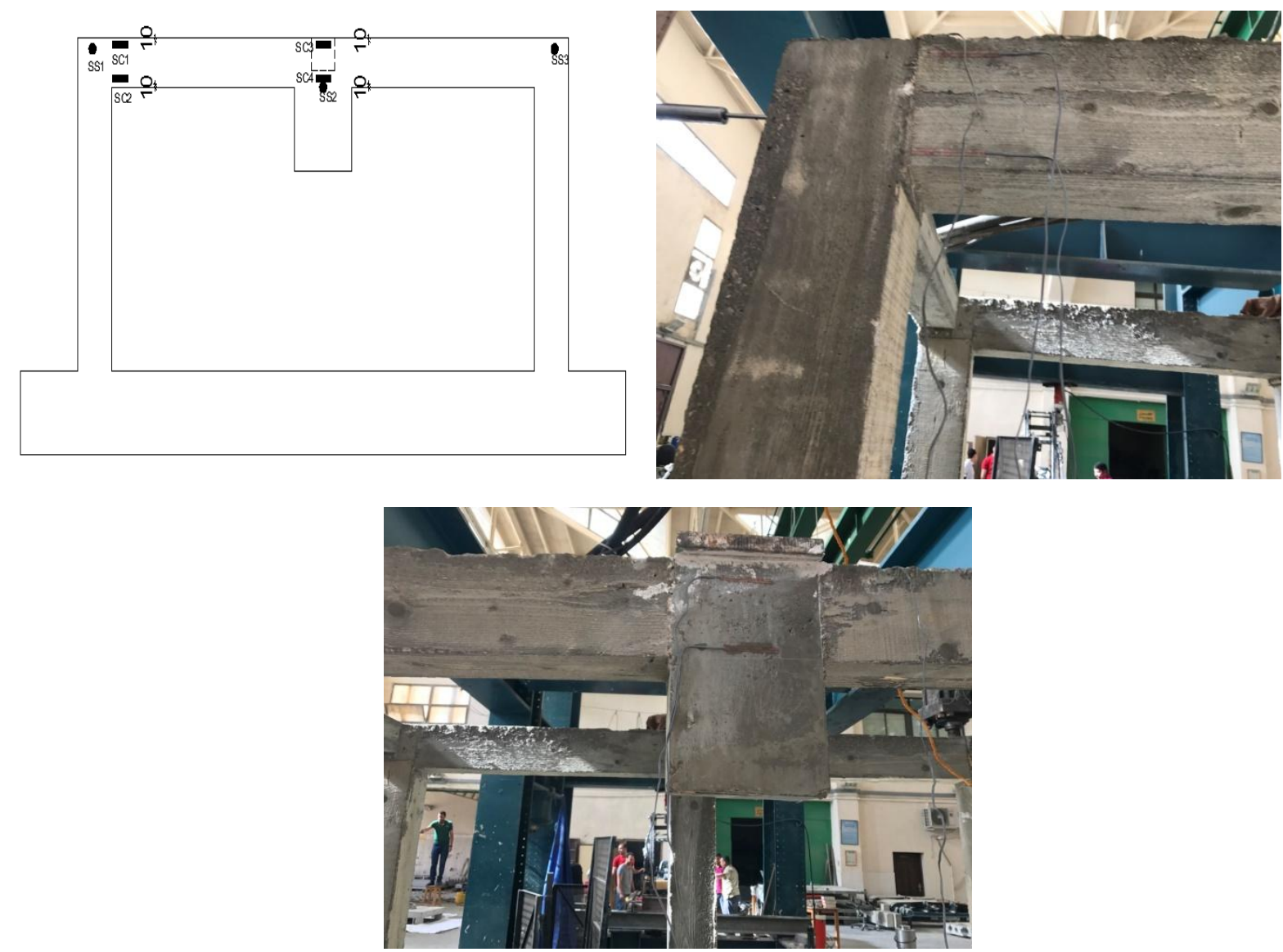

Figure (8): The locations of and uniaxial strain gauges

\subsubsection{Loading Procedure}

Hydraulic actuator was installed at the top of middle column (A-2) to apply vertical load in succession as shown in figure (9). Column (A-2), as mentioned earlier, is not supported to simulate the loss of a column. It is easy to 
observe and investigate the redistribution and transferring of internal force after the loss of middle column in the frame using this loading method. The load was applied with time as one ton per second until failure.

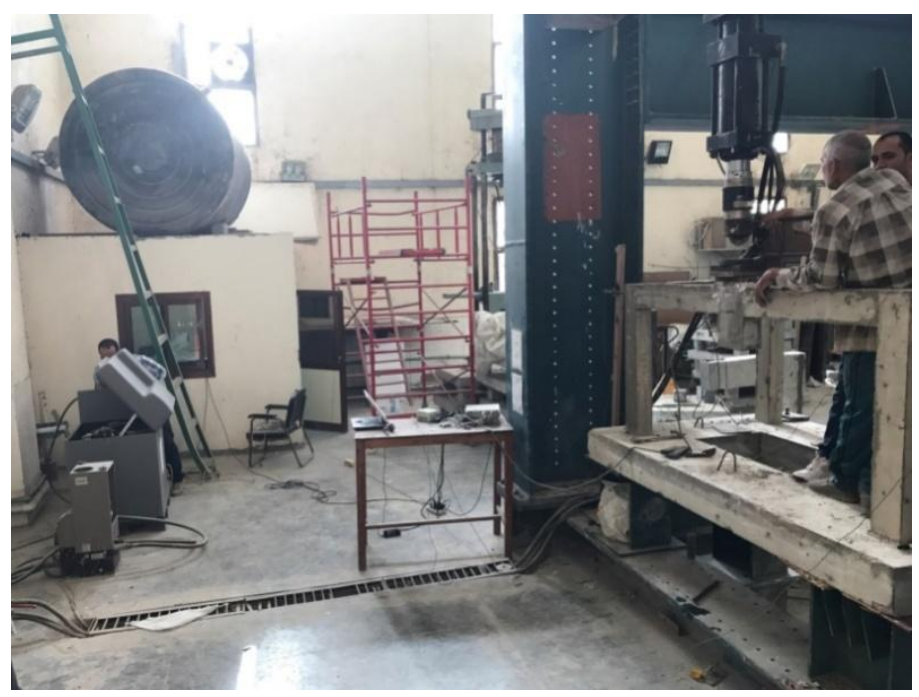

Figure (9): Electric hydraulic jack machine and test setup

\section{Analysis and Discussion of Results}

\subsection{Mode of Failure}

Figure (10) showsthe mode of failure of tested frame. It is clear that the damage occurred beside the column (A-2) and at joints of columns (A-1) and (A-3). Besides, there was damage that observed in the transverse beam.

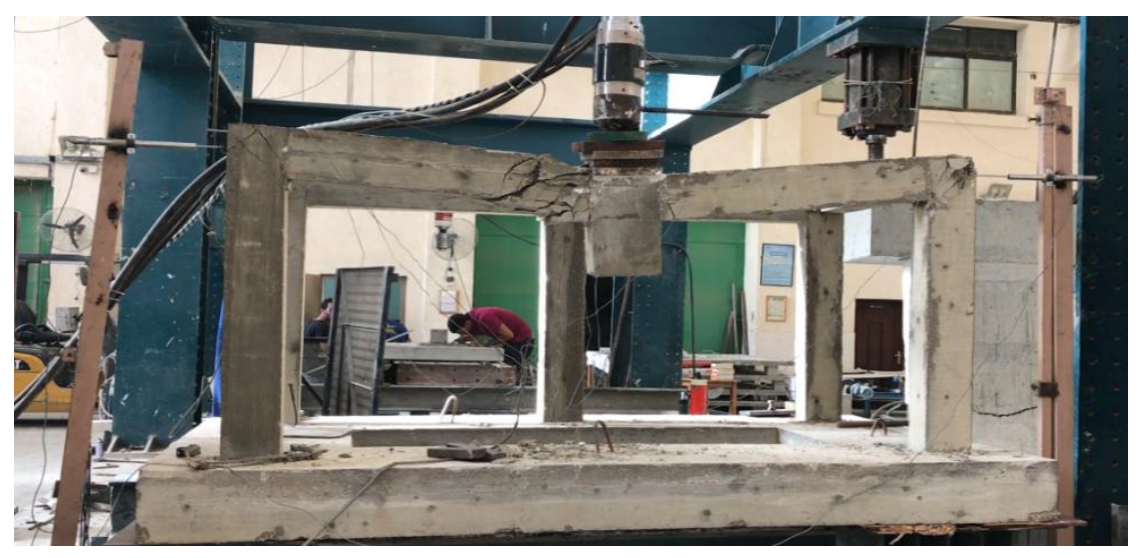

Figure (10):The failure mode of the frame

\subsection{Relationship of vertical displacement v.s. vertical load}

Figure (11) shows the load-vertical displacement relationship curve of middle column (A-2) where no support is provided. As shown in figure, the curve consists of four stages: elastic stage, elastic-plastic stage, arch stage and plastic stage. The part OA of the curve shows the first stage-"elastic stage". In this stage, the load-deflection relationship can be considered to be linear as the specimen is almost elastic and the deformation is small. When the load reached $12 \mathrm{kN}$, the curve goes into the second stage-"elastic-plastic stage". In this stage, from point A to point $\mathrm{B}$, the load begins to increase non-linearly with the increment of displacement, while the stiffness begins to 
decrease. The third stage from point $B$ to point $C$ is named as "Arch stage", in which the curve presents a trend as arch. In this stage, the load increases with the increasing of vertical displacement of column (A-2). However, after reaching peak point, the load decreases by increasing the vertical displacement of column (A-2). The load at point B and point $\mathrm{C}$ is equal. The peak value of $60.5 \mathrm{kN}$ is defined as "Peak resistance" while the load value of $55 \mathrm{kN}$ at point $\mathrm{B}$ and point $\mathrm{C}$ is defined as "Plastic resistance". The increase of resistance is caused by "Arch action". As the vertical load applying on the top of column (A-2), the joint of column (A-2) is subjected to a sagging moment while the adjacent joints are subjected to hogging moments. Therefore, when the vertical load applies, "arch action" is formed by treating the rotation center of joint withstanding sagging moment as arch crown and the rotation center of joints withstanding hogging moment as arch spring. Similarly, "arch action" also exists in RC structures [18], which is because of the asymmetry of reinforcement distribution in RC beams. Arch action is beneficial to the resistance of frame with column failure which would produce a higher resistance than the traditional plastic resistance. When the elevation of rotation centers becomes identical under vertical load, it means the end of "arch stage. The fourth stage from point $\mathrm{C}$ to point $\mathrm{D}$ is defined as "plastic stage", while plastic hinges are fully formed in the joint $\mathrm{C}$ and inner side joints of column (A-1) and (A-3). In this stage, the vertical displacement of column (A-2) rises from $40 \mathrm{~mm}$ to $49 \mathrm{~mm}$, while the vertical load remains about $52 \mathrm{Kn}$. "Ultimate resistance" is defined as the maximum resistance of frame before the collapse happens. The ultimate resistance observed is $49 \mathrm{kN}$, which is 0.81 times of peak resistance and The corresponding ultimate vertical displacement is $52 \mathrm{~mm}, 2.2$ times bigger than peak displacement correspondent to peak resistance.

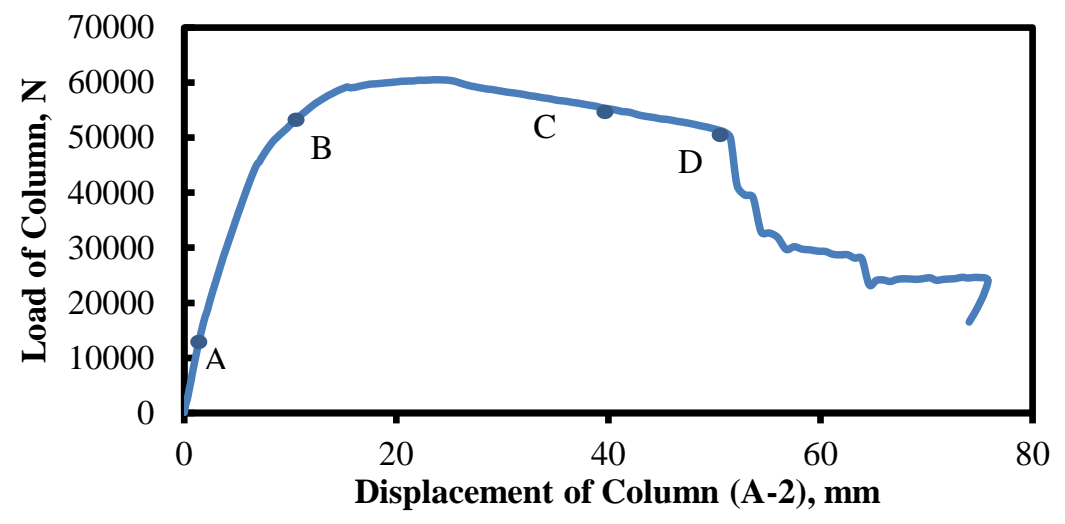

Figure (11): Vertical load - displacement of middle column

\subsection{Relationship of Horizontal Displacement v.s. Vertical Displacement}

Figure (12) shows the relationship curves of vertical displacement of column (A-2) v.s. horizontal displacements of columns (A-1) and (A-3). Deformation towards column (A-2) is defined as positive value. As shown in figure, in the early stage of loading, the horizontal displacement of each column is negative value which means that all the columns deform outwards from column (A-3). After the vertical deflection reaches the displacement at point $\mathrm{B}$, the horizontal deformation becomes to be positive value. The maximum negative value of horizontal deformation observed is $-0.1 \mathrm{~mm}$. In the arch stage the horizontal displacement of column (A-1) and (A-3) increase from $1.8 \mathrm{~mm}$ to $6 \mathrm{~mm}$. In the plastic stage the horizontal displacement of columns (A-1) and (A-3) remains around $6 \mathrm{~mm}$ until failure occur. 


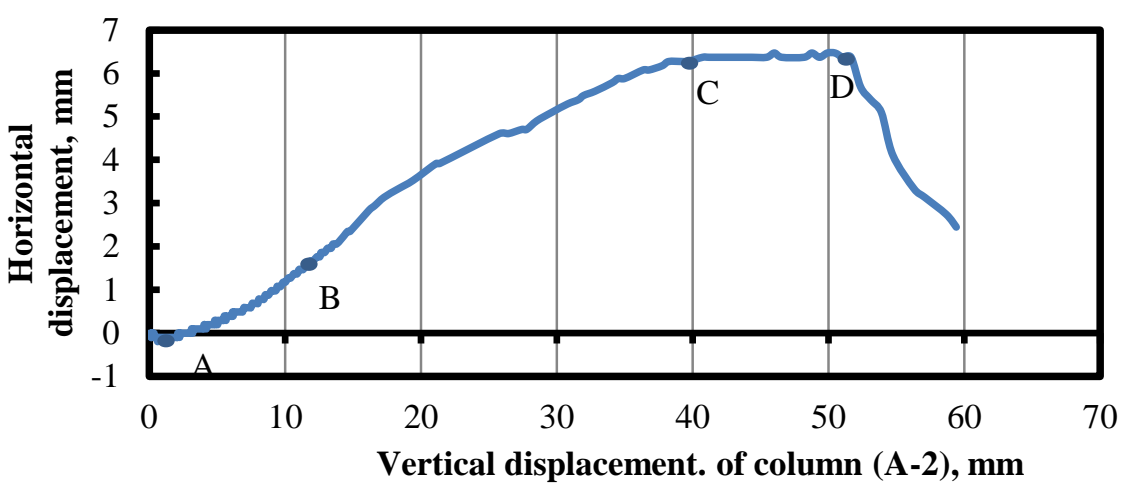

Figure (12): Horizontal displacement of column (A-1)\&(A-3) - vertical displacement of middle column.

\subsection{Measurements of Strain Gauges}

To measure he internal behavior of frame, three electronic strain gauges used to measure strain of reinforcement with time and load and four electronic strain gauges used to measure strain of concrete with time and load. Figure (13) shows the value of strain reinforcement steel pars. It is clearly to show that the strain of main steel ss1and ss 2 was exceeded the yield strain of steel $(2000 \mu \mathrm{m} / \mathrm{m})$. The strain ss1 reached the yielding at load $58 \mathrm{kn}$ and reached $2600 \mu \mathrm{m} / \mathrm{m}$ at failure load $60.25 \mathrm{kn}$. The strain ss 2 reached the yielding at load $45 \mathrm{kn}$ and reached $4800 \mu \mathrm{m} / \mathrm{m}$ at failure load $60.25 \mathrm{kn}$. The strain of ss 3 didn't exceed the yielding. These values can be seen in the failure mode that occurred.

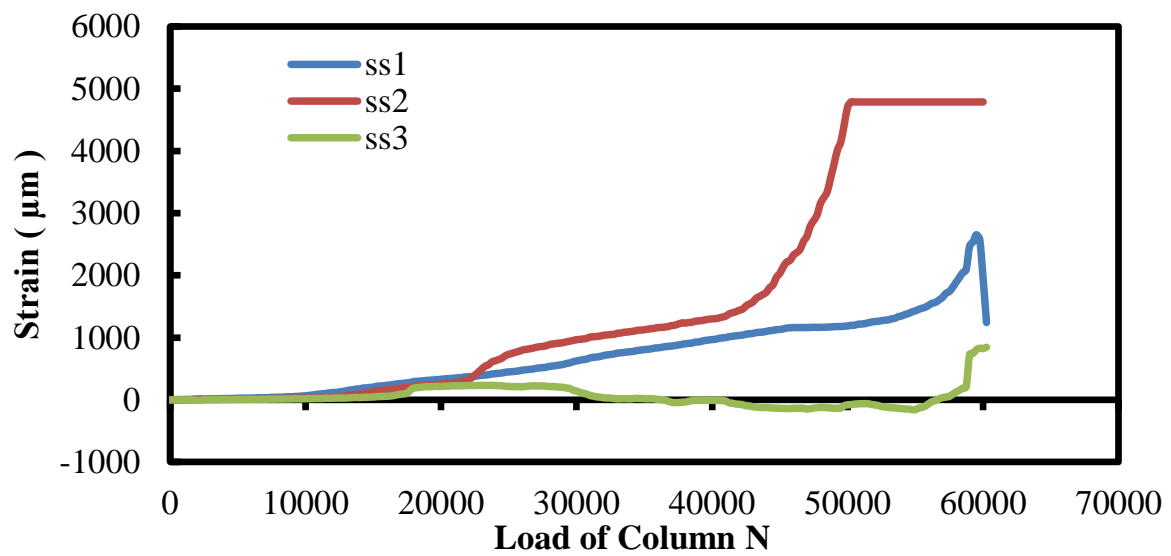

Figure (13): Measurements of strain gauges of steel with time

As shown in figure (14), for sc1 the relation between load and strain began liner then second linear relation continued up to yield load then the relation took curve up to failure, it appears that the tension strain in concrete was $668 \mu \mathrm{m} / \mathrm{m}$ at yield load $45 \mathrm{kn}$, at failure it was noticed that the maximum compression strain in concrete reached $1188 \mu \mathrm{m} / \mathrm{m}$, for $\mathrm{sc} 2$ the relation between load and strain began liner then second linear relation continued up to yield load then the relation took curve up to failure, it appears that the compression strain in concrete was $544 \mu \mathrm{m} / \mathrm{m}$ at yield load $45 \mathrm{kn}$, at failure it was noticed that the maximum compression strain in concrete reached $1809 \mu \mathrm{m} / \mathrm{m}$, for sc3 the relation between load and strain began liner then second linear relation continued up to yield load then the relation took curve up to failure, it appears that the compression strain in concrete was $484 \mu \mathrm{m} / \mathrm{m}$ at yield load $45 \mathrm{kn}$, at failure it was noticed that the maximum compression strain in concrete reached $692 \mu \mathrm{m} / \mathrm{m}$, for sc4 the relation between load and strain began liner then second linear relation continued up to yield load then the relation took curve up to failure, it appears that the tension strain in concrete was $608 \mu \mathrm{m} / \mathrm{m}$ at yield load $45 \mathrm{kn}$, at failure it was noticed that the maximum compression strain in concrete reached $655 \mu \mathrm{m} / \mathrm{m}$. 


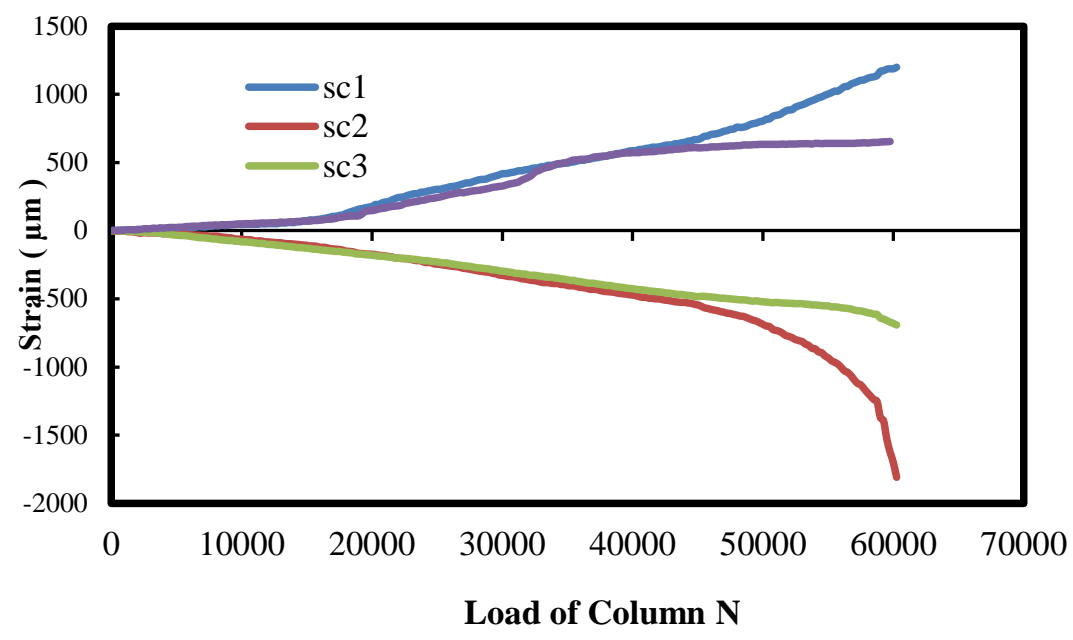

Figure (14): Measurements of strain gauges of concrete with load

\section{Numerical Analysis}

In addition to the experimental work, finite element program Abaqus is used to develop the numerical simulation of the test above. The reinforced concrete frame investigated in this study was modeled use 3-D solid elements. In the model reinforcement were modeled as truss element with the embedded region constrain.

\subsection{Material model properties}

Several reviews of the properties of concrete in both tension and compression under dynamic loading have been completed recently. More emphasis is typically placed on the compressive behavior, for which more data is available, and less on the tensile response. The effect of strain rate on the concrete compressive and tensile strengths is typically reported as a dynamic increase factor (DIF) - i.e. the ratio of dynamic to static strength - versus strain rate, on a semi-log or log-log scale. This is a convenient format for implementation into numerical models. In particular the CEB Model Code [19] reports DIFs for compressive and tensile strengths under high rates of loading, based both on test results and analytical models.

\section{a) Compression in CEB Model}

In compression, the CEB model appears to properly fit the available data. The dynamic increase factor (DIF) for the compressive strength, is given by equation (1):

$\frac{f_{C}}{f_{C S}}=\left[\frac{\varepsilon^{\bullet}}{\varepsilon^{*}{ }_{s}}\right]^{1.026 \propto s} \quad$ For $\varepsilon^{\cdot} \leq s^{\cdot-1}$

$=\gamma_{s}\left[\frac{\varepsilon^{\bullet}}{\varepsilon^{\bullet}}\right]^{0.3333} \quad$ For $\varepsilon^{\bullet}>30 s^{\bullet-1}$

Where $\quad f_{c}=$ dynamic compressive strength at $\varepsilon^{\bullet}$

$f_{c S}=$ static compressive strength at $\varepsilon^{\bullet}{ }_{s}$

$\frac{f_{C}}{f_{c S}}=$ compressive strength dynamic increase factor (DIF)

$\varepsilon^{\bullet}=$ strain rate in range of $30 \times 10^{-6}$ to $300 \mathrm{~s}^{-1}$

$\varepsilon^{\bullet}{ }_{s}=30 \times 10^{-6} \mathrm{~S}^{-1}$ (static strain rate)

$\log \gamma=6.156 \propto-2$ 
$\gamma_{s}=1 /\left(5+9 \frac{f_{c s}}{f_{c 0}}\right)$

$f_{c 0}=10 \mathrm{Mpa}$

\section{b) Tension in CEB Model}

The dynamic increase factor (DIF) for the tensile strength, is given by equation (2):

$\frac{f_{t}}{f_{t s}}=\left[\frac{\varepsilon^{*}}{\varepsilon_{s}^{*}}\right]^{1.016 \delta} \quad$ For $\varepsilon^{\cdot} \leq 30 s^{\cdot-1}(2)$

$={ }_{\beta}\left[\frac{\varepsilon^{*}}{\varepsilon_{s}^{*}}\right]^{0.3333} \quad$ For $\varepsilon^{\bullet}>30 s^{\cdot-1}$

Where $\quad f_{t}=$ dynamic tensile strength at $\varepsilon^{\bullet}$

$f_{t s}=$ static tensile strength at $\varepsilon^{\cdot}$

$\frac{f_{t}}{f_{t s}}=$ tensile strength dynamic increase factor (DIF)

$\varepsilon^{\cdot}=$ strain rate in range of $30 \times 10^{-6}$ to $300 \mathrm{~s}^{-1}$

$\varepsilon^{\bullet}{ }_{s}=3 \times 10^{-6} \mathrm{~s}^{-1}$ (static strain rate)

$$
\log _{\beta}=7.11 \delta-2.33
$$

In the analysis of reinforced concrete structures subjected to dynamic loading, both concrete and steel are subjected to very high strain rates. The applied load in experimental test was increased by rate 1 ton per second. The experimental investigation of strain at linear zone was $52 \mathrm{~s}^{-1}$ in compression and $77 \mathrm{~s}^{-1}$ in tension. Using the previous equations, the DIF was 1.67 and 2.2 for compression and tension respectively. Figure (15) shows the compressive and tension behavior at static and dynamic load.

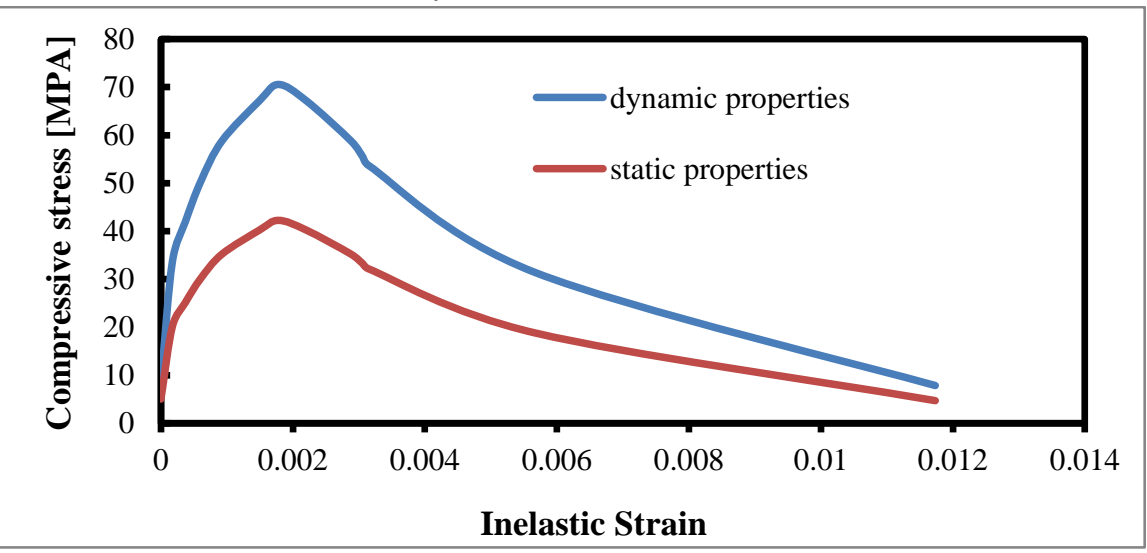

a) Compressive stress-strain behavior 


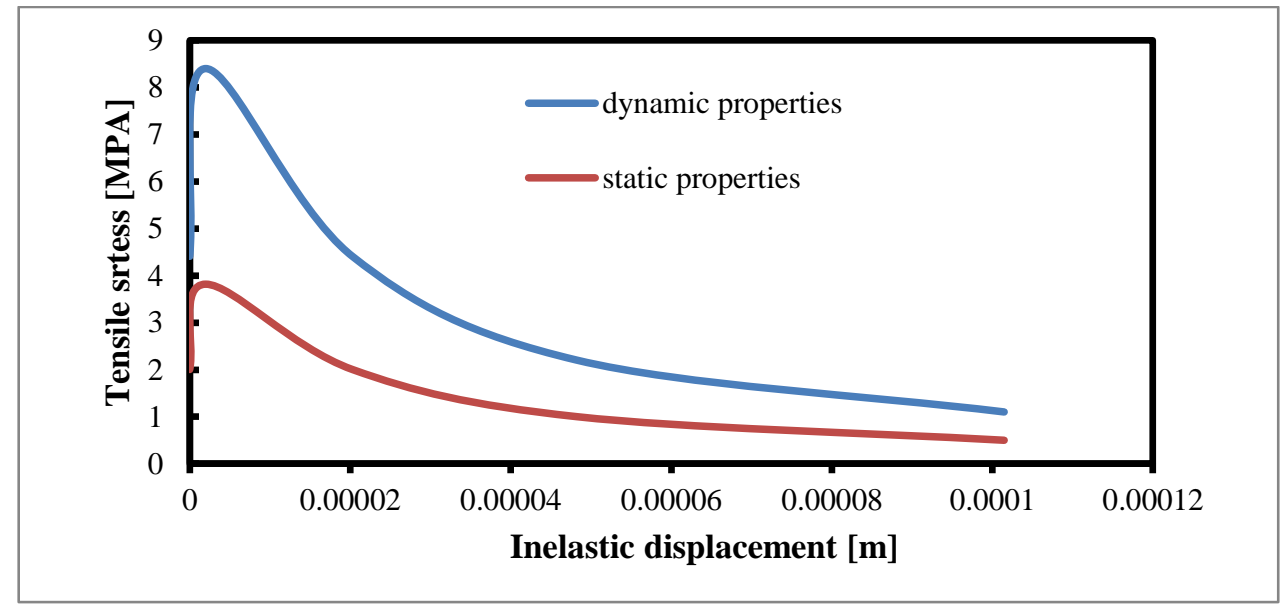

b) Tensile stress- displacement behavior

Figure (15): The compressive and tension behavior at static and dynamic load.

The concrete strength used in the test was 42MPa denoted in this study as (C 40). The main parameters needed to define the concrete model after computation of failure compression and tension strength at high strain rates are summarized in table (2).

Table (2): Data defines (C 40 MPA) material

\begin{tabular}{|l||l||}
\hline Density $\left(\mathrm{kg} / \mathrm{m}^{3}\right)$ & 2570 \\
\hline \hline Young's Modulus: $E(\mathrm{MPa})$ & 25,200 \\
\hline \hline Poisson's ratio & 0.2 \\
\hline \hline Dilation angle & 20 \\
\hline \hline Yield stress in compression $(\mathrm{MPa})$ & 8.4 \\
\hline \hline Elastic strain at yield stress & 0.0 \\
\hline \hline Compressive ultimate stress $(\mathrm{MPa})$ & 70.5 \\
\hline \hline Inelastic strain & 0.00178 \\
\hline \hline Failure stress in compression $(\mathrm{MPa})$ & 7.8 \\
\hline \hline Strain at failure & 0.0056 \\
\hline \hline Ultimate tensile stress $(\mathrm{MPa})$ & 8.4 \\
\hline \hline Tension stiffening & $2 \times 10^{-6}$ \\
\hline
\end{tabular}

\section{c) Elastic-plastic model}

Steel reinforcement bars have approximately linear elastic behavior when the steel stiffness introduced by the Young's or elastic modulus keeps constant at low strain magnitudes. At higher strain magnitudes, it begins to have nonlinear, inelastic behavior, which is referred to as plasticity. The plastic behavior of steel is described by its 
yield point and its post-yield hardening. The shift from elastic to plastic behavior occurs at a yield point on a material stress-strain curve. The deformation of the steel prior to reaching the yield point creates only elastic strains, which is fully recovered if the applied load is removed. However, once the stress in the steel exceeds the yield stress, permanent (plastic) deformation begins to occur. Both elastic and plastic strains accumulate as the metal deforms in the post-yielding region. The stiffness of the steel decreases once the material yields. The plastic deformation of the steel material increases its yield stress for subsequent loadings. To define the elastic properties of reinforcement bar material, only the values of Young's modulus (E) and the Poisson's ratio of the steel (v) have to be specified while plastic properties of reinforcement steel used are defined as a nonlinear stress-strain curve in tabular form. The main parameters needed to define the reinforcement bar models for both longitudinal bars and stirrups are summarized in tables (3) and (4) respectively.

Table (3): Data defines longitudinal steel material.

\begin{tabular}{|l|l||}
\hline \hline Reference density $\left(\mathrm{kg} / \mathrm{m}^{3}\right)$ & 7800 \\
\hline \hline Young's Modulus, E $(\mathrm{MPa})$ & 200,000 \\
\hline \hline Tensile Strength, $\mathrm{ft}(\mathrm{MPa})$ & 345 \\
\hline
\end{tabular}

Table (4): Data defines stirrups steel material.

\begin{tabular}{|l||l||}
\hline Reference density $\left(\mathrm{kg} / \mathrm{m}^{3}\right)$ & 7800 \\
\hline \hline Young's Modulus, E $(\mathrm{MPa})$ & 200,000 \\
\hline \hline Tensile Strength, ft $(\mathrm{MPa})$ & 250 \\
\hline
\end{tabular}

\section{Results of the numerical model}

\subsection{Load-deflection curves}

The comparison between the displacements obtained from experimental work and finite element analysis for frame showed good agreement with results obtained from experimental work as shown in figure (16) and (17).

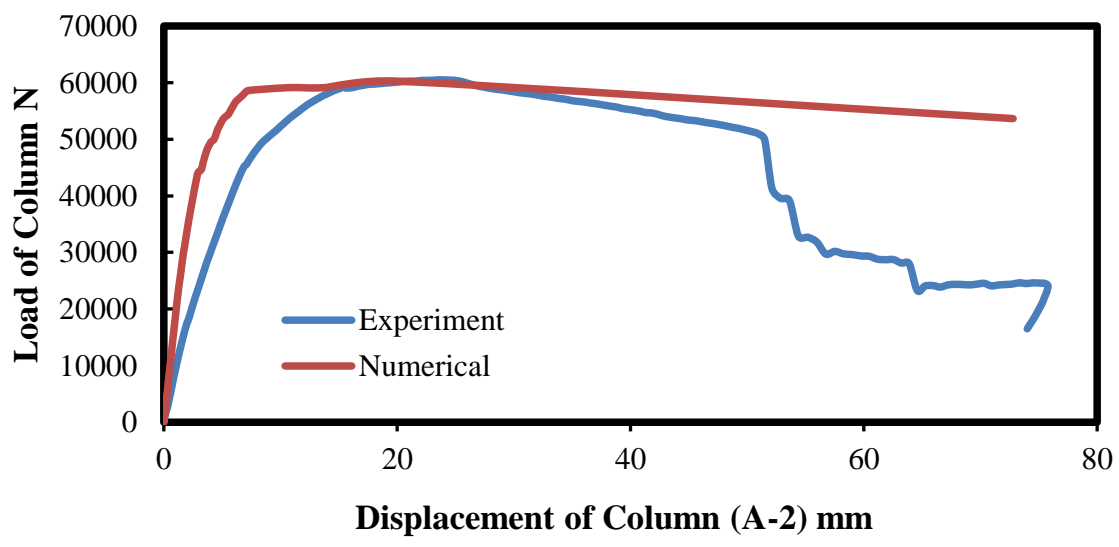

Figure(16): Vertical load - displacement relationship of middle column 


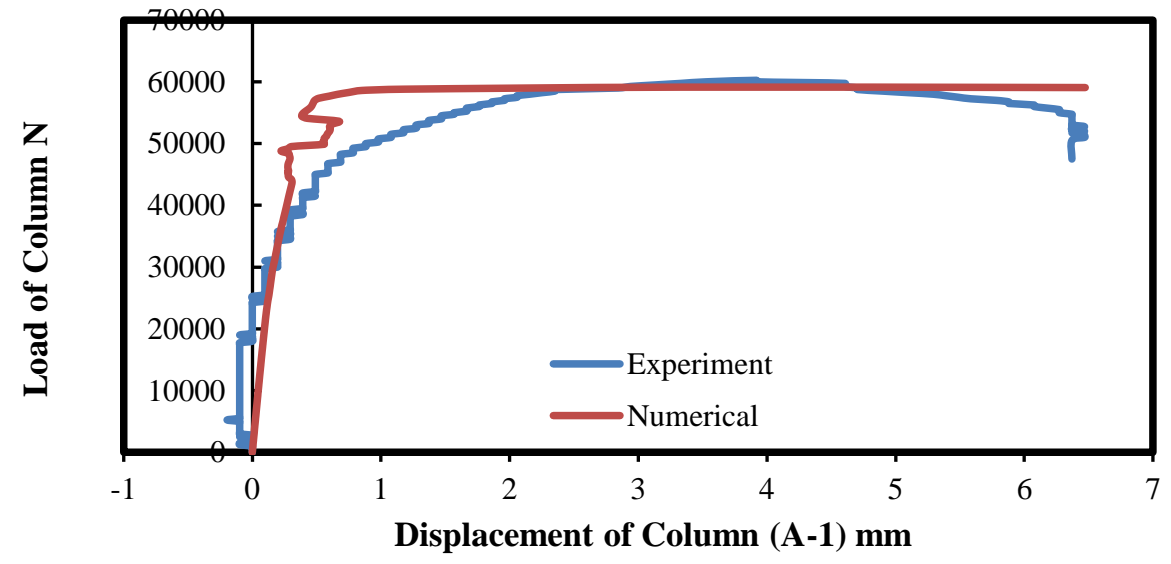

Figure (17): Vertical load - Horizontal displacement relationship of column (A-1)

\subsection{Mode of failure of the $\mathrm{RC}$ frame}

A comparison between the failure mode obtained from experimental work and finite element analysis for frame showed good agreement between results obtained from experimental work and finite element analysis as shown infigures(18) to (22).

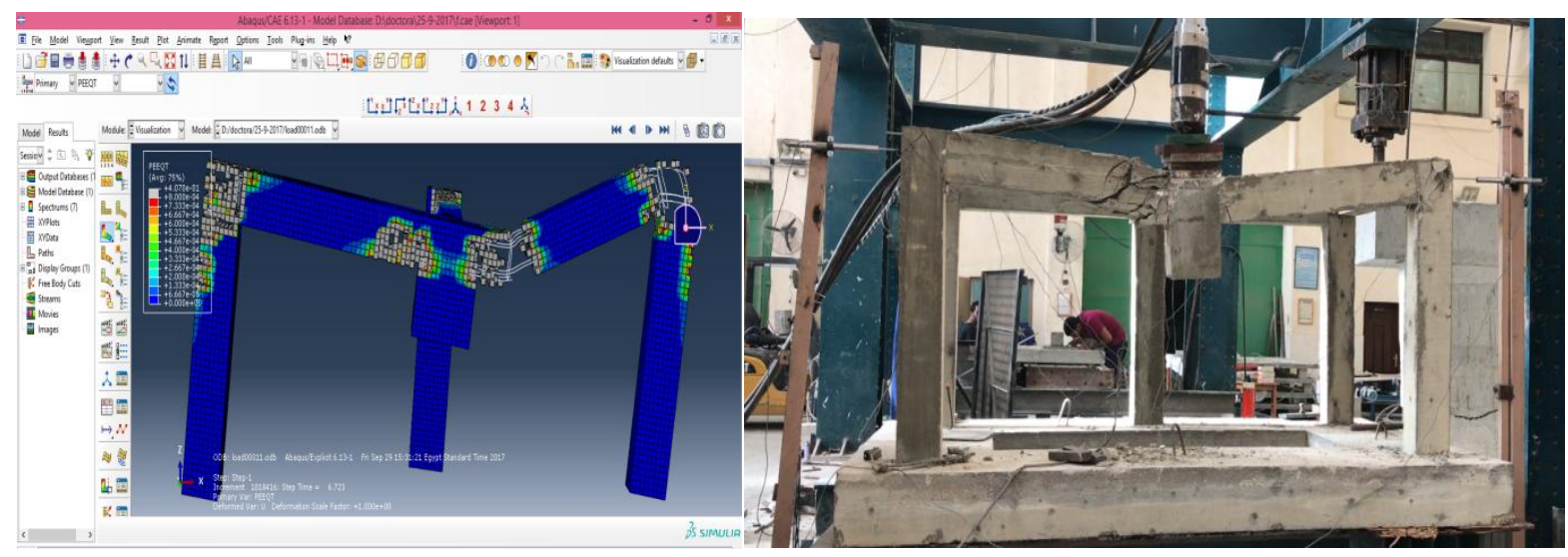

Figure (18): General mode of failure

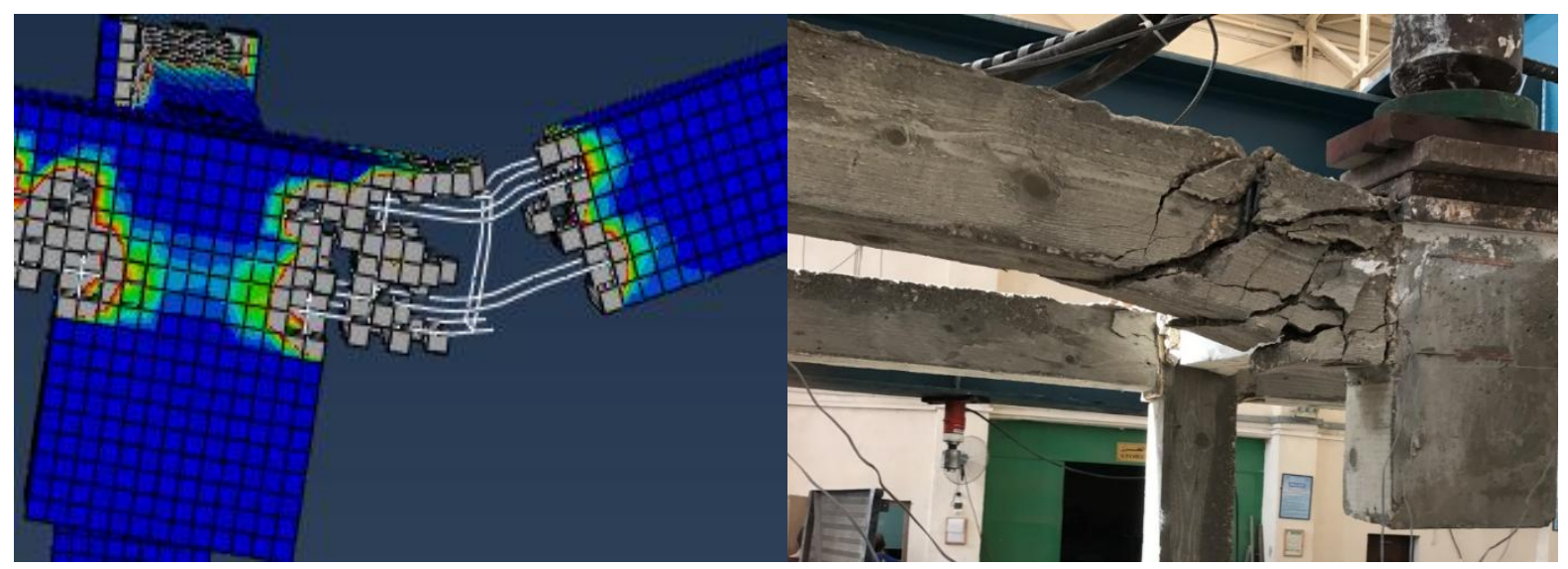

Figure (19): Failure of connection (2) 


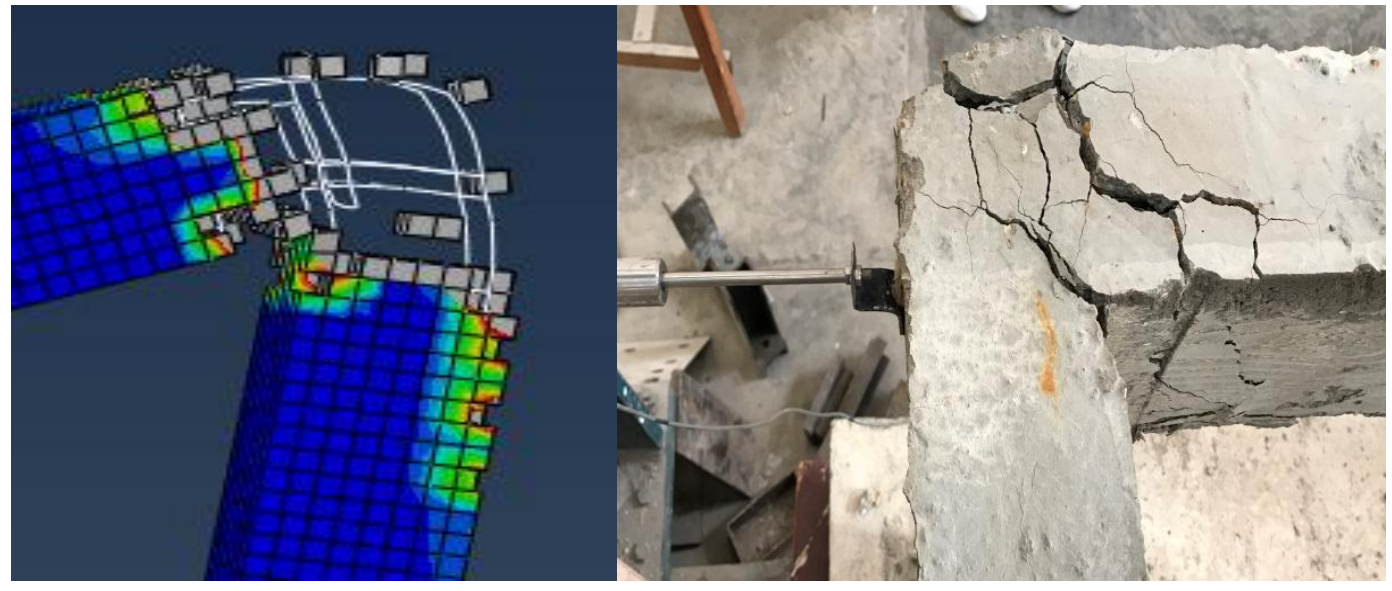

Figure (20): Failure of connection (1)

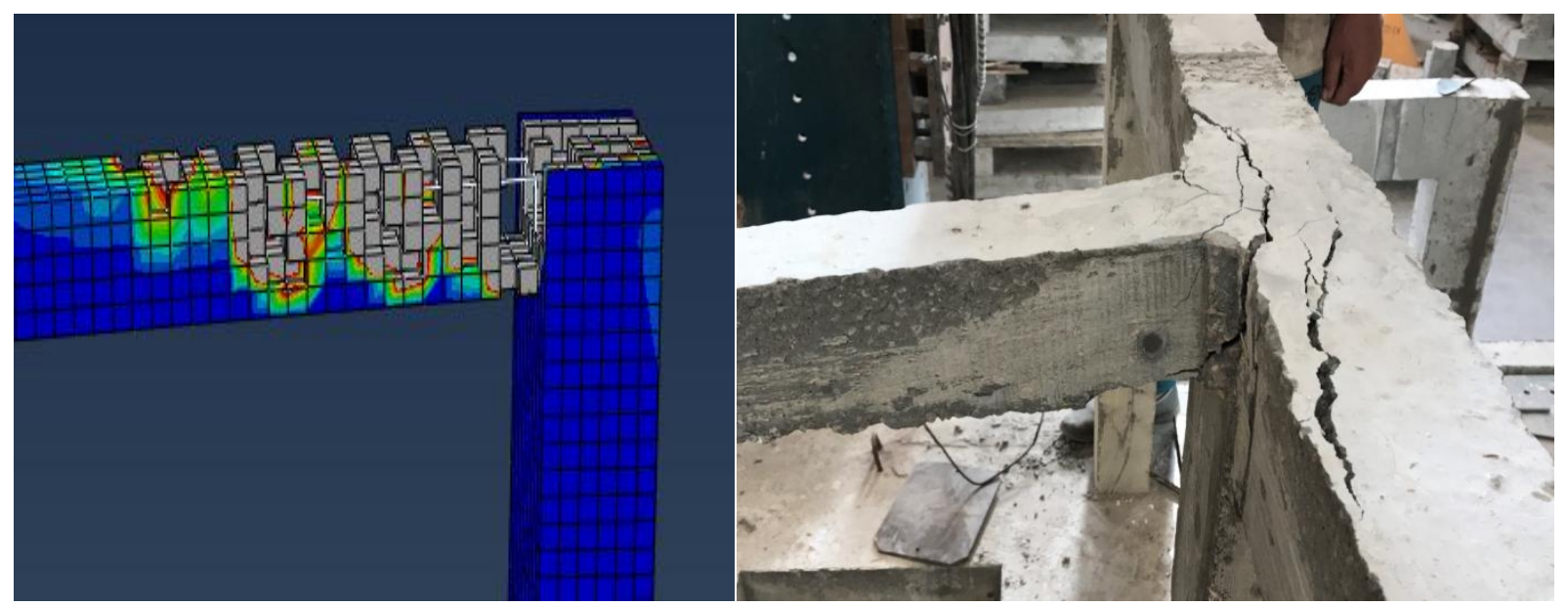

Figure (21): Failure of transverse beam

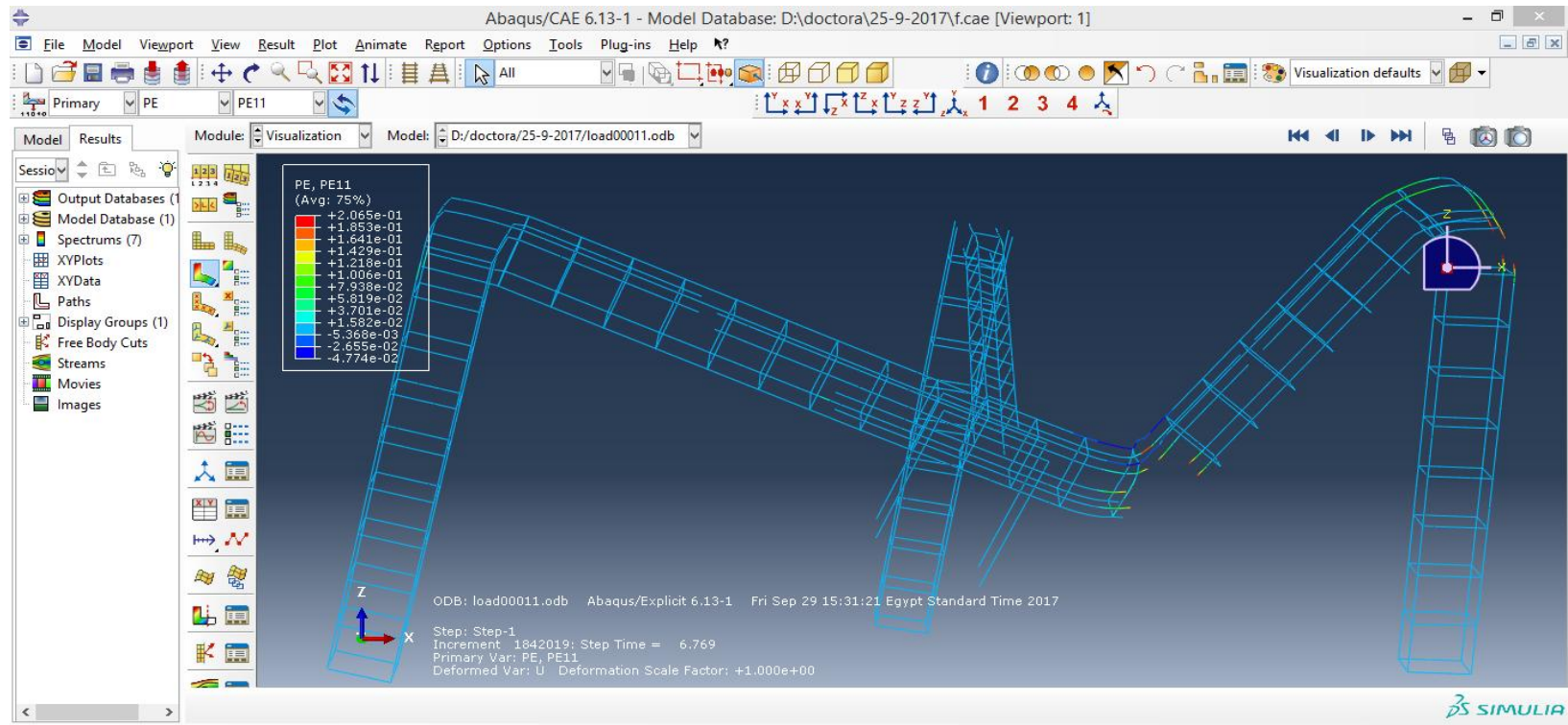




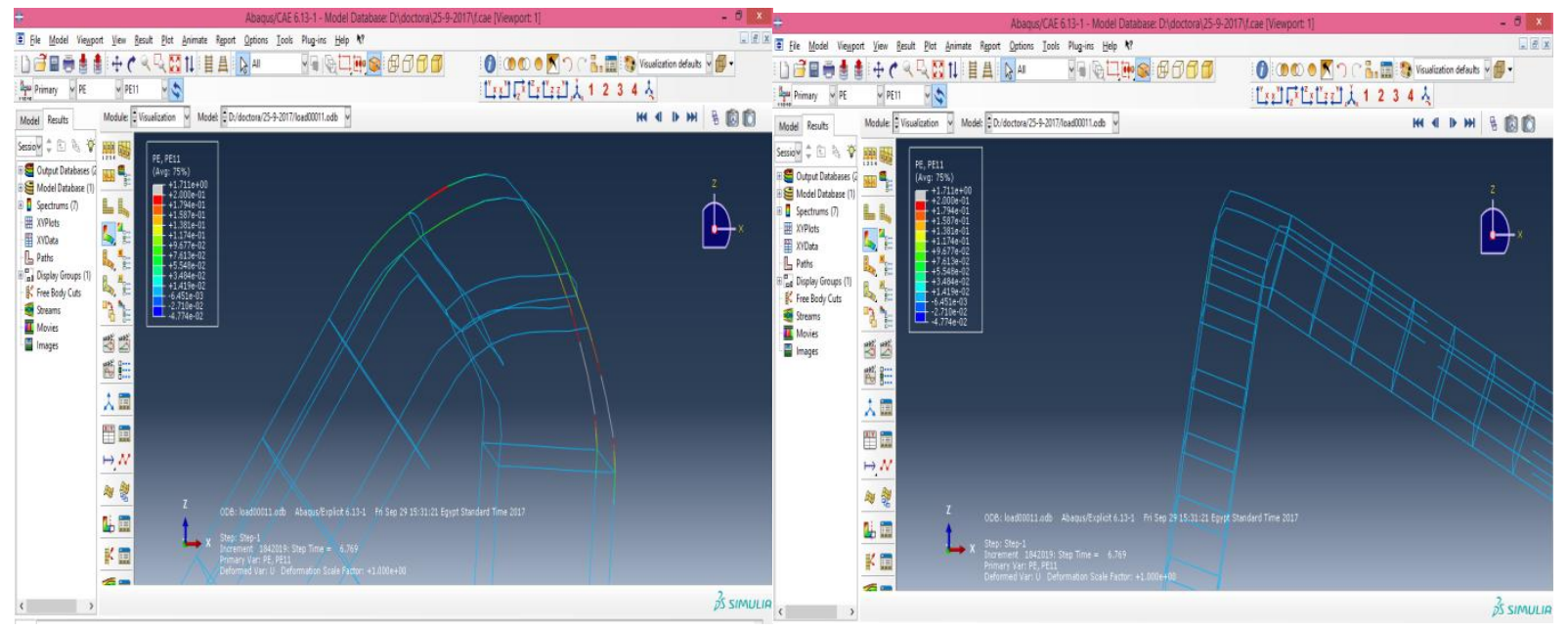

Figure (22): Maximum plastic strain occurs in steel bars.

It can be seen that the yielding occurred in main steel reinforcement obtained from experimental work and finite element analysis for frame showed good agreement between results obtained. The yielding occurred near to connection 2 and in the upper of connection 1 of column (A-3). And it can be seen that no yielding occurred at main steel in connection 1 of column (A-1) that was occurred in experimental work.

\section{Conclusions}

Based on the results and observations of the experimental study and the numerical analysis presented, the following conclusions could be drawn as follows:

1- The collapse process of RC frame after one column removal consists of four stages: elastic stage, elasticplastic stage, arch stage and plastic stage.

2- The ultimate resistance observed in the experiment is $49 \mathrm{kN}$, which is 0.81 times of peak resistance and the corresponding ultimate vertical displacement is $52 \mathrm{~mm}, 2.2$ times bigger than peak displacement correspondent to peak resistance.

3- Beside the damage occurred in connections 1 and 2. There was damage that observed in the transverse beam. This indicated that the effect of this beam on the total behavior of the frame couldn't be neglected through considering 2D structure only.

4- During design stage, special care should be paid to the lower reinforcement of columns' connections as this reinforcement will resist the vertical deflection of the joint if a sudden failure occurred to the column.

5- Concrete at high strain rate has higher properties in both tension and compression which significantly affects the structural behavior in the numerical model.

6- The presented F.E model shows an excellent agreement regarding to mode of failure with the experimental model.

\section{References}

[1] GSA Guidelines. GSA progressive collapse analysis and design guidelines for new federal office buildings and major modernizations projects.General Services Administration (GSA); 2003.

[2] DoD UFC Guidelines.Design of buildings to resist progressive collapse, Unified Facilities Criteria (UFC) 4-023-

03. Department of Defence (DoD); 2005. 
[3] NIST Best Practices. Best practices for reducing the potential for progressive collapse in buildings. US National Institute of Standards and Technology (NIST), Washington, DC; 2007.

[4] Nair RS. Preventing disproportionate collapse. J Perform Construct Facilit 2006; 20(4):309-14.

[5] Mohamed OA. Progressive collapse of structures: annotated bibliography and comparison of codes and standards. J Perform Construct Facilit 2006; 20(4):418-25.

[6] Starossek U. Progressive collapse of structures. Thomas Telford Ltd; 2009.

[7] Kokot S. Literature survey on current methodologies of assessment of building robustness and avoidance of progressive collapse. JRC Scientific and Technical

Reports JRC 5598, European Commission, Joint Research Centre; 2009.

[8] Starossek U. Typology of progressive collapse. EngStruct 2007; 29 (9):2301-7.

[9] Marjanishvili S, Agnew E. Comparison of various procedures for progressive collapse analysis. J Perform Construct Facilit 2006; 20 (4):365-74.

[10] Fu F. 3-d nonlinear dynamic progressive collapse analysis of multi-storey steel composite frame buildings parametric study. EngStruct 2010; 32:3974-80.

[11] Tsai MH, Lin BH. Investigation of progressive collapse resistance and inelastic response for an earthquakeresistant RC building subjected to column failure. EngStruct 2008; 30:3619-28.

[12] Kwasniewski L. Nonlinear dynamic simulations of progressive collapse for a multistory building.EngStruct 2010; 32(5):1223-35.

[13] Iribarren BS, Berke P, Bouillard P, Vantomme J, Massart T. Investigation of the influence of design and material parameters in the progressive collapse analysis of RC structures. Engineering Structures, in press.Doi: 10.1016/ j.engstruct.2011.06.005.

[14]Wang,Wei, Wang, Junjie, Sun, Xin, Bao, Yihai,(2016). "Slab effect of composite subassemblies under a column removal scenario", Department of Civil and Environmental Engineering, University of California, Davis, CA 95616, USA

[15]Bo Yang,Bo.,Tan.,KangHai, Xiong,Gang,(2015). "Behaviour of composite beam-column joints under a middlecolumn-removal scenario: Component-based modeling", Chongqing University, Chongqing 400045, PR China

[16] Egyptian Code of Practice (ECCP203-2007), "Design and Construction for Reinforced Concrete Structures". Research Center for Houses Building and Physical Planning, HBRC, 2007Structures" National Research Center for Housing, Building and Physical Planning.

[17] International Organization for Standardization (EOS1658-4/2008, International organization for standardization (ISO 1920-3:2004), Testing of concrete, part 3, Making and curing test specimens.

[18] Izzuddin BA, Vlassis AG, Elghazouli AY, Nethercot DA. Progressive collapse of multi-storey buildings due to sudden column loss-Part 1: simplified assessment framework. EngStruct 2008;30(5):1308-18.

[19]Comité Euro-International du Béton, CEB-FIP Model Code 1990, Redwood Books,Trowbridge, Wiltshire, UK, 1993. 